Original Article

\title{
NOVEL HPTLC-DENSITOMETRIC METHOD FOR THE ESTIMATION OF TERIFLUNOMIDE IN TABLET DOSAGE FORM
}

\section{T. S. VISHWAS, B. M. GURUPADAYYA*, RUPSHEE JAIN}

Department of Pharmaceutical Chemistry, JSS College of Pharmacy, JSS Academy of Higher Education and Research, Mysuru 570015, India Email: bmgurupadayya@jssuni.edu.in

Received: 28 Dec 2018 Revised and Accepted: 02 May 2019

\section{ABSTRACT}

Objective: The current work is intended towards the development of a novel, simple and precise high-performance thin layer chromatographic (HPTLC) method coupled with a densitometer for the estimation of teriflunomide (TEF) present in the marketed formulation.

Methods: The chromatographic development was performed on aluminum plates coated with silica gel $60 \mathrm{~F}_{254}$ using toluene: ethyl acetate: glacial acetic acid (7.5:2: $0.5 \mathrm{v} / \mathrm{v} / \mathrm{v}$ ) as the mobile phase. Densitometric scanning was achieved at the absorbance maxima, UV $284 \mathrm{~nm}$.

Results: Well separated band was observed with Rf value 0.46 . The calibration curve plotted in the concentration range 100-700ng/band exhibited an excellent linear relationship with the $\mathrm{r}^{2}$ value of 0.9928 . The method was found to comply with all the validation parameters as per the ICH guidelines.

Conclusion: The method ensures minimal use of mobile phase with minimal run time compared to other reported analytical methods. This validated method can be used by quality control laboratories for the routine quantitative analysis of tablets consisting of Teriflunomide.

Keywords: Densitometer, HPTLC, ICH guidelines, Marketed formulation, Teriflunomide, UV

(C) 2019 The Authors. Published by Innovare Academic Sciences Pvt Ltd. This is an open-access article under the CC BY license (http://creativecommons.org/licenses/by/4.0/) DOI: http://dx.doi.org/10.22159/ijpps.2019v11i6.31742

\section{INTRODUCTION}

Teriflunomide (fig. 1) (TEF) is an orally administered, secondgeneration immunosuppressive/immunomodulatory agent which is an active metabolite of Leflunomide. It acts by inhibiting dihydroorotate dehydrogenase, an enzyme which is responsible for pyrimidine de novo synthesis [1-4]. It is permitted by both the US Food and Drug Administration (FDA) and the European Medicines Agency (EMA) as a disease-modifying therapy (DMT's) for adults with relapsing-remitting multiple sclerosis (RRMS). This drug, not official any pharmacopeias like IP, USP and BP.

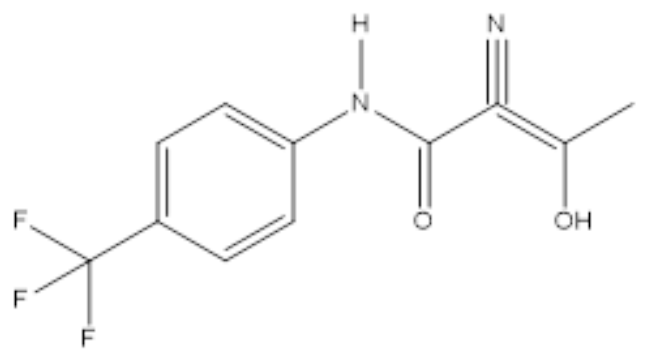

Fig. 1: Teriflunomide

The literature survey disclosed various methods for the estimation of TEF in API, marketed formulations and biological fluids. The detailed information on the various methods available are as follows; chromatographic methods such as HPLC [5, 6], UPLC [7], RP-HPLC $[8,9]$, LC-MS [10-13]. In all the reported techniques, the overall solvent consumption, cost per analysis and overall time required for analysis were much more. Furthermore, No HPTLC method has been reported so far, for the estimation of TEF in the marketed formulation. Therefore, the current work is directed towards the development of a novel HPTLC method for the determination of TEF in the marketed formulation having sensitivity in terms of nanogram with minimal development time, minimal use of solvents and its validation according to ICH guidelines.

\section{MATERIALS AND METHODS}

\section{Materials and reagents}

Teriflunomide pure drug (API) was procured as a gift sample from Glenmark Ltd., Noida. All the other reagents used were of analytical grade and were procured from Merck specialties, private limited, Mumbai, India. Marketed Formulation (Denopsy tablets, Natco Pharma, Hyderabad) was purchased from a local pharmacy.

\section{HPTLC instrumentation and chromatographic conditions}

CAMAG HPTLC system equipped with Linomat 5 sample applicator operated under a gentle stream of nitrogen, coupled with a $100 \mu \mathrm{l}$ HAMILTON syringe and a CAMAG TLC scanner 3controlled by winCATS software was used for the application and detection of spots respectively. Aluminum sheets having a dimension of $20 \times 10$ $\mathrm{cm}$, coated with silica gel $60 \mathrm{~F}_{254}$ procured from Merck, Germany and a CAMAG twin trough TLC chamber having a dimension $27.0 \mathrm{~cm}$ width $\times 26.5 \mathrm{~cm}$ height $\times 7.0 \mathrm{~cm}$ was used for the chromatographic development

For chamber saturation, $20 \mathrm{ml}$ of the mobile phase was transferred into the development tank with the lid closed. The assembly was kept aside for 20 min under room temperature. The plates were air dried using an air dryer after the application of spots and after the development, prior to densitometric scanning. The chromatographic conditions were as described in table 1.

\section{Preparation of standard solutions}

A stock solution containing $1000 \mathrm{ng} / \mu \mathrm{l}$ of TEF was prepared by using acetonitrile as a diluent. $0.5 \mathrm{ml}$ of this solution was pipetted out into a $10 \mathrm{ml}$ volumetric flask and the volume was made up, to get a working solution consisting of $50 \mathrm{ng} / \mu \mathrm{l}$ of TEF. 
Table 1: HPTLC Chromatographic conditions

\begin{tabular}{ll}
\hline Parameters & Values \\
\hline Mobile phase & Toluene: Ethyl acetate: Glacial acetic acid (7.5:2: 0.5 v/v/v) \\
The volume of mobile phase used & $20 \mathrm{ml}$ \\
Chamber saturation time & $20 \mathrm{~min}$ \\
Band length & $6 \mathrm{~mm}$ \\
Dosage speed & $150 \mathrm{nl} / \mathrm{s}$ \\
Distance between bands & $10 \mathrm{~mm}$ \\
Development time & $7 \mathrm{~min}$ \\
Detector wavelength & $284 \mathrm{~nm}$ \\
Rf value & 0.46 \\
\hline
\end{tabular}

\section{Preparation of sample solution (Formulation)}

As specified in the label, each tablet contains $14 \mathrm{mg}$ of TEF. The weight of 10 tablets was noted and crushed using a mortar and pestle, the quantity of powder equivalent to $10 \mathrm{mg}$ of teriflunomide was transferred to a $10 \mathrm{ml}$ volumetric flask and the volume was made up with acetonitrile. The required dilutions were made to get a final concentration of $50 \mathrm{ng} / \mu \mathrm{l}$.

\section{Method validation}

The method was validated according to ICH guidelines for the following parameters: Linearity, accuracy, precision, the limit of detection (LOD) and limit of quantification (LOQ), specificity and robustness [14-16].

\section{RESULTS AND DISCUSSION}

\section{Optimization of chromatographic conditions}

The ideal mobile phase of the method was selected after several experimental trials. Solvents like acetonitrile, methanol, toluene, ethyl acetate used initially; did not provide a clear spot. Therefore, various permutations and combinations of these solvents were used for the trials. Out of all the combinations, toluene and ethyl acetate was found to give a spot. For better resolution, $0.5 \%$ glacial acetic acid was added. Thus, the final chromatographic condition, toluene: ethyl acetate: glacial acetic acid in the ratio 7.5: 2: $0.5(\mathrm{v} / \mathrm{v} / \mathrm{v})$ was able to achieve a clear spot with good $\mathrm{R}_{\mathrm{f}}$ value. Increasing the volume of glacial acetic acid leads to an increase in the $\mathrm{R}_{\mathrm{f}}$ value and vice versa. The chamber saturation time was found to show a similar effect.

The wavelength for the densitometric scanning of the spots was selected after obtaining the UV spectra of TEF (fig. 2), which showed the maximum absorbance at $284 \mathrm{~nm}$.

\section{Linearity}

The calibration curve (fig. 3) was plotted between peak areas versus concentration. The linearity of TEF was constructed by applying 7 bands in the concentration range of $100-700 \mathrm{ng} /$ band. The regression equation ( $\mathrm{r} 2=0.9928)$ demonstrated the good linearity of the method. The slope and intercept of the regression equation were 15.471 and 3505.7 respectively for TEF. The linearity was found to be satisfactory and reproducible. The calibration curve of linearity and overlay densitogram of TEF is depicted in fig. 3 and 4 respectively.

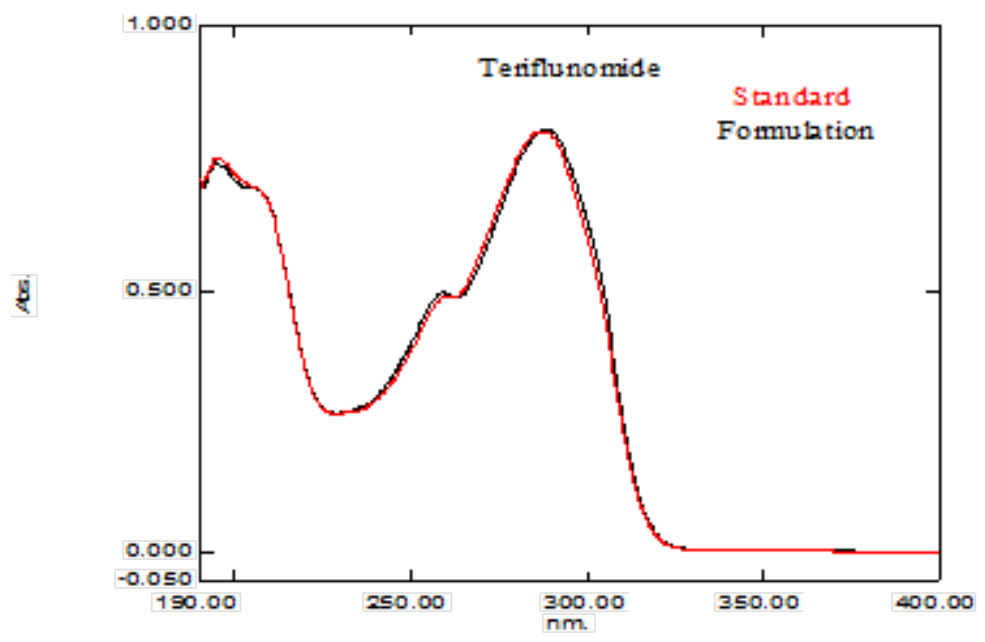

Fig. 2: Overlay UV absorption spectra of TEF standard and formulation

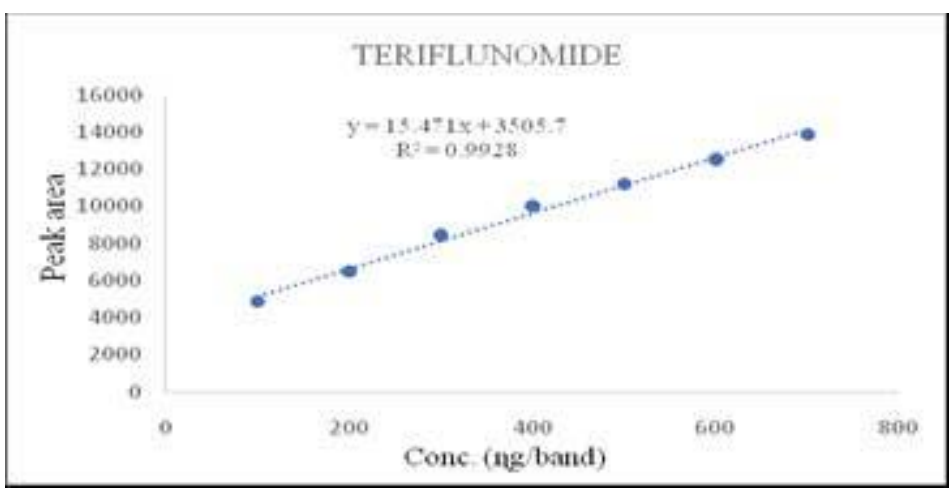

Fig. 3: Calibration curve of TEF 


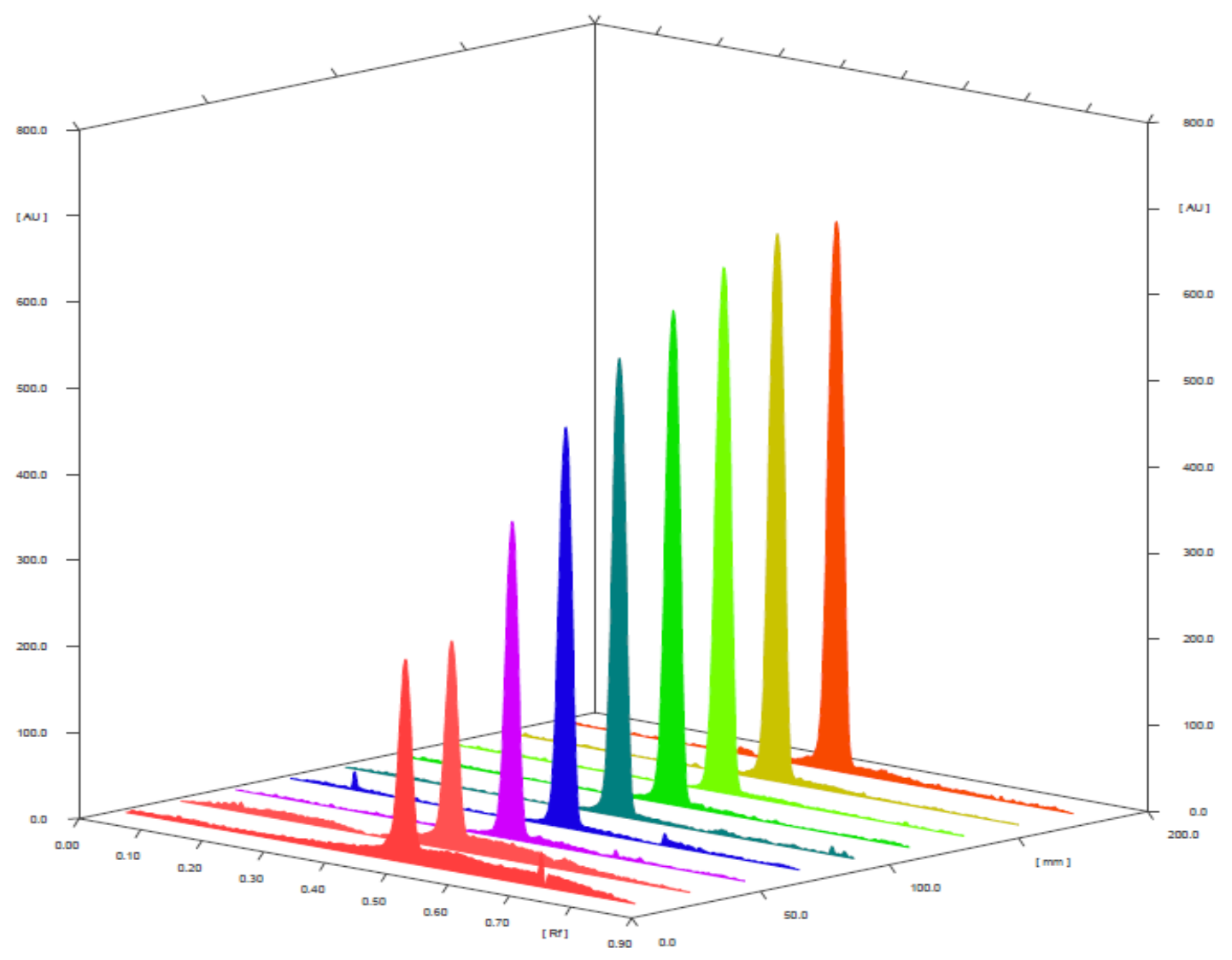

Fig. 4: Overlay densitogram of TEF

\section{Accuracy}

Accuracy was assessed in terms of percentage recovery, by spiking the band of the formulation with $50 \%, 100 \%, 150 \%$ of pure drug and then finding out the amount of the drug recovered. The mean percentage of recovery was found to be $99 \%$, as depicted in table 2 .

Table 2: Accuracy study of TEF

\begin{tabular}{|c|c|c|c|c|c|}
\hline $\begin{array}{l}\text { Level of recovery } \\
(\%)\end{array}$ & $\begin{array}{l}\text { Amount of formulation } \\
\text { (ng/band) }\end{array}$ & Amount of pure drug (ng/band) & \% Recovery & Mean & \% RSDa \\
\hline \multirow[t]{3}{*}{50} & 100 & 50 & 99.20 & & \\
\hline & 100 & 50 & 98.04 & $98.94 \pm 0.9$ & 0.668 \\
\hline & 100 & 50 & 99.60 & & \\
\hline \multirow[t]{3}{*}{100} & 100 & 100 & 100.10 & & \\
\hline & 100 & 100 & 99.80 & $99.7 \pm 0.4$ & 0.287 \\
\hline & 100 & 100 & 99.40 & & \\
\hline \multirow[t]{3}{*}{150} & 100 & 150 & 99.60 & & \\
\hline & 100 & 150 & 98.00 & $98.6 \pm 1.0$ & 0.721 \\
\hline & 100 & 150 & 98.20 & & \\
\hline
\end{tabular}

aMean for three independent analyses, SD=Standard deviation, RSD=Relative standard deviation

\section{Precision}

Intraday and interday precision of the method was assessed by developing the plate after application of 6 replicates of the highest concentration on the TLC plate on the same day and the consecutive day respectively. Precision was reported in terms of \%RSD. The $\%$ RSD values were found to be less than $2 \%$ as depicted in table 3 , indicating the high precision of the developed method.

Table 3: Precision study of TEF

\begin{tabular}{lll}
\hline Precision studies & Intraday & Interday \\
\hline Conc. $(\mathrm{ng} /$ band) & 700 & 700 \\
Average peak area $(\mathrm{n}=6)$ & 13830.5 & 13734.17 \\
Standard deviation & 101.8361 & 124.8431 \\
$\% \mathrm{RSD}^{\mathrm{a}}$ & 0.7363 & 0.9089 \\
\hline
\end{tabular}

aMean for six independent analyses, SD=Standard deviation, RSD=Relative standard deviation. 


\section{Limit of detection and limit of quantitation}

LOD and LOQ were calculated with the aid of standard deviation $(\sigma)$ and slope (s) from the calibration curve $(\mathrm{n}=3)$, by using the formula $\mathrm{LOD}=3.3 \mathrm{\sigma} / \mathrm{s}$ and LOQ $=10 \mathrm{\sigma} / \mathrm{s}$. LOD and LOQ of TEF were found to be $21 \mathrm{ng} / \mathrm{band}$ and $65 \mathrm{ng} / \mathrm{band}$ respectively, which indicates the good sensitivity of the method towards the analyte.

\section{Specificity}

The specificity of the method was assessed by comparing the UV absorption spectra (fig. 2) and densitogram of standard (fig. 4) TEF with the formulation (fig. 5). The densitogram of both standard and formulation showed the same $\mathrm{R}_{\mathrm{f}}$ value indicating the good specificity of the method.

\section{Robustness}

The robustness was assessed by making small but deliberate changes in the method parameters such as; mobile phase ratio, chamber saturation time, scanning wavelength and finding out its effect on the peak area by calculating \%RSD. The \% RSD was found to be within $2 \%$, which indicates the reliability of the method. The robustness of the method are depicted in table 4.

Table 4: Robustness study of TEF

\begin{tabular}{ll}
\hline Parameters & \% RSD $^{\mathbf{a}}$ \\
\hline Mobile phase composition $( \pm 2 \mathrm{ml})$ & 1.35 \\
Chamber saturation time $( \pm 2 \mathrm{~min})$ & 0.98 \\
Scanning wavelength $( \pm 2 \mathrm{~nm})$ & 1.72 \\
\hline
\end{tabular}

aMean for five independent analyses, $\mathrm{SD}=\mathrm{Standard}$ deviation, $\mathrm{RSD}=$ Relative standard deviation.

\section{Analysis of formulation}

The $\%$ of a drug found in the formulation of the currently developed method was found to be $98.9 \%$. The densitogram obtained from the formulation (fig. 5) exhibited a single spot at $\mathrm{R}_{\mathrm{f}} 0.46$ without any interference of the excipients. The close agreement of the percentage of the drug found with label claims depicted the application of this method for the routine analysis of TEF present in its formulation.

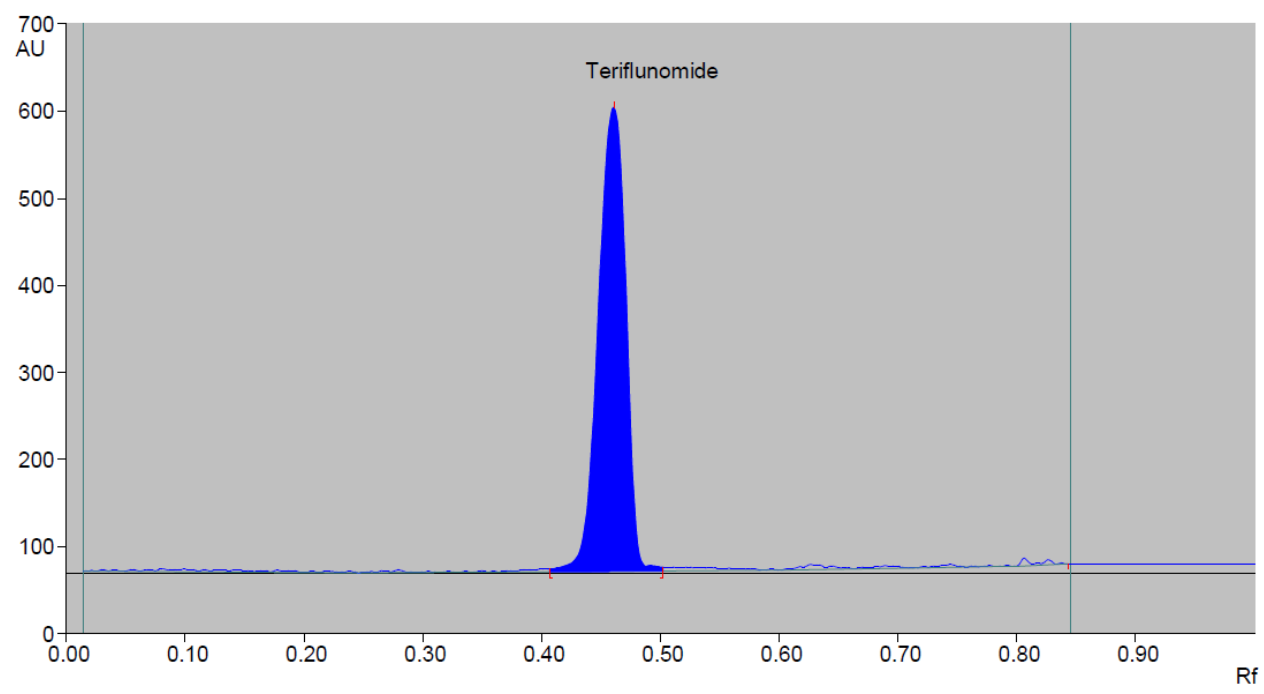

Fig. 5: Densitogram of the formulation

\section{DISCUSSION}

A novel, simple and precise high-performance thin layer chromatographic (HPTLC) method coupled with densitometer was developed for the estimation of TEF present in the marketed formulation. There are some HPLC methods $[7,8]$ reported in the literature, but they have certain restrictions like require a large quantity of sample and/or organic solvents or sensitive to microgram concentration. Few methods like Liquid chromatography-mass spectroscopy for determination TEF in human or animal plasma [9-12] etc. are found in the literature, but these methods are not preferred for routine analysis of TEF in bulk and formulation studies, because of the high cost of analytical technique and the skilled requirement for sample treatment. A detailed evaluation of the analytical method procedures discussed with the present method was given in table 1 . Accuracy results displayed good reproducibility with \% RSD values below 2 . This was found to be accurate as percent recovery observed was high i.e. within the range of 98.6-98.94\%, suggesting that the proposed method showed good agreement between the standard and the observed values and demonstrate an adequate accuracy within the specified limits as shown in the table 2. Furthermore, detection limit depends upon the instrument sensitivity as low detection limits give high sensitivity. The LOD and LOQ of developed for HPTLC method was found to be $21 \mathrm{ng} / \mathrm{ml}$ and $65 \mathrm{ng} / \mathrm{ml}$ respectively confirms method is sensitive. Results of intra and inter-day precision studies were expressed as \%RSD, the results were given in table 3 . The low values of \%RSD showed that the method is precise. The results of robustness are tabulated in table 4 , the method is not altered by changing the method parameters like mobile phase composition, chamber saturation time and scanning wavelength which proves that the method is robust. In addition, the estimation of the marketed preparation of TEF with the validated methods showed that the drug contents separated with no interfering peaks generated by the excipients in the marketed formulation as shown in the fig. 5 . The method is versatile and simple for the analysis TEF in pure and pharmaceutical formulations. The method was found to obey all the validation parameters as per the ICH guidelines. The method confirms minimal use of the mobile phase with a short run time compared to other reported analytical methods. This validated method can be used for quality control laboratories for the routine quantitative analysis of tablets consisting of TEF. 


\section{CONCLUSION}

A novel, simple, rapid and precise HPTLC method coupled with densitometer scanning has been developed for the determination of TEF in the marketed formulation. This validated method can be used by quality control laboratories for the routine quantitative analysis of tablets consisting of TEF. The additives used in this formulation were also not interfering with the analysis. The method ensures minimal use of mobile phase with minimal run time compared to other reported analytical methods. Non-requirement of skilled personnel to operate the instruments involved is an added advantage of this method.

\section{ACKNOWLEDGMENT}

The authors extend their gratitude to the PES College of Pharmacy, Bangalore for giving an opportunity to carry out work in their college.

\section{AUTHORS CONTRIBUTIONS}

The submitted research work is a part of the Master of Pharmacy in Pharmaceutical Analysis specialization. This project was guided by Dr. BM Gurupadayya and laboratory research work and validation of the method was carried out by Mr. T S Vishwas with the coordination of Dr. Rupshee Jain.

\section{CONFLICT OF INTERESTS}

The authors report no conflicts of interest

\section{REFERENCES}

1. Marriott JJ, O'Connor PW. Emerging therapies in relapsingremitting multiple sclerosis. Rev Recent Clin Trials 2010;5: $179-88$.

2. Bruneau JM, Spinella Jaegle S, Fudali C, Woodward K, Robson PA, Sautes C, et al. Purification of human dihydro-orotate dehydrogenase and its inhibition by A77 1726, the active metabolite of leflunomide. Biochem J 1998;336:299-303.

3. O'connor PW, Li D, Freedman MS, Bar-Or A, Rice GP, Confavreux C, et al. A Phase II study of the safety and efficacy of teriflunomide in multiple sclerosis with relapses. Neurology 2006;66:894-900.

4. Helliwell CL, Coles AJ. Monoclonal antibodies in multiple sclerosis treatment: current and future steps. Ther Adv Neurol Disord 2009;2:195-203.

5. Sobhani K, Garrett DA, Liu DP, Rainey PM. A rapid and simple high-performance liquid chromatography assay for the leflunomide metabolite, teriflunomide (A77 1726), in renal transplant recipients. Am J Clin Pathol 2010;133:454-7.

6. Schmidt A, Schwind B, Gillich M, Brune K, Hinz B. Simultaneous determination of leflunomide and its active metabolite, A77 1726, in human plasma by high-performance liquid chromatography. Biomed Chromatogr 2003;17:276-81.

7. Nadella NP, Ratnakaram VN, Srinivasu N. Quality-by-designbased development and validation of a stability-indicating UPLC method for quantification of teriflunomide in the presence of degradation products and its application to in vitro dissolution. J Liq Chromatogr Relat Technol 2017;40:517-27.

8. Mehta B, Prajapat P, Gohil Y. Development and validation of stability indicating RP-HPLC method for estimation of teriflunomide in an active pharmaceutical ingredient. J Pharm Innov 2017;6:440-9.

9. Parekh JM, Vaghela RN, Sutariya DK, Sanyal M, Yadav M, Shrivastav PS. Chromatographic separation and sensitive determination of teriflunomide, an active metabolite of leflunomide in human plasma by liquid chromatographytandem mass spectrometry. J Chromatogr B 2010;878:2217-25.

10. Rakhila H, Rozek T, Hopkins A, Proudman S, Cleland L, James M, et al. Quantitation of total and free teriflunomide (A77 1726) in human plasma by LC-MS/MS. J Pharm Biomed Anal 2011;55:325-31.

11. Rule GS, Rockwood AL, Johnson Davis KL. LC-MS/MS method for determination of teriflunomide, over a 40,000-fold dynamic range using overlapping calibrators. Ther Drug Monit 2015;37:472-8.

12. Suneetha A, Raja RK. Comparison of LC-UV and LC-MS methods for simultaneous determination of teriflunomide, dimethyl fumarate and fampridine in human plasma: application to rat pharmacokinetic study. Biomed Chromatogr 2016;30:1371-7.

13. International Conference on Harmonization, "Q2A: Text on Validation of Analytical Procedures. Federal Register 1995;60:11260-2.

14. International Conference on Harmonization, "Q2B: Validation of analytical procedures: Methodology. Federal Register 1996;62:27463-7.

15. Vaishali M, Akshay Y, Amey D. A simultaneous estimation, validation and forced degradation studies of 5-fluorouracil and tegafur in a pharmaceutical dosage form using reversed-phase high-performance liquid chromatography method. Asian J Pharm Clin Res 2018;11:132-7.

16. Pratima S, Ravinder K, Govind A. Simultaneous estimation of thiocolchicoside and aceclofenac by HPTLC. Int J Curr Pharm Res 2017;9:55-60. 